\title{
Minimal impact of age and housing temperature on the metabolic phenotype of $\mathrm{Acc2}^{-/-}$mice
}

\author{
Amanda E Brandon ${ }^{1,2}$, Ella Stuart ${ }^{1}$, Simon J Leslie', Kyle L Hoehn ${ }^{4}$, David E James ${ }^{5}$, \\ Edward W Kraegen ${ }^{1,3}$, Nigel Turner ${ }^{3}$ and Gregory J Cooney ${ }^{1,2}$ \\ 'Diabetes and Metabolism Division, Garvan Institute of Medical Research, 384 Victoria Street, Darlinghurst, \\ New South Wales 2010, Australia \\ ${ }^{2}$ St Vincent's Clinical School, University of New South Wales Australia, Sydney, New South Wales, Australia \\ ${ }^{3}$ School of Medical Sciences, University of New South Wales Australia, Sydney, New South Wales, Australia \\ ${ }^{4}$ School of Biotechnology and Biomolecular Sciences, University of New South Wales Australia, Sydney, \\ New South Wales, Australia \\ ${ }^{5}$ School of Molecular Bioscience and Sydney Medical School, Charles Perkins Centre, The University of Sydney, \\ Sydney, New South Wales, Australia
}

Correspondence should be addresses to G J Cooney Email g.cooney@garvan.org.au

\begin{abstract}
An important regulator of fatty acid oxidation (FAO) is the allosteric inhibition of CPT-1 by malonyl-CoA produced by the enzyme acetyl-CoA carboxylase 2 (ACC2). Initial studies suggested that deletion of $A c c 2$ ( $A c a c b)$ increased fat oxidation and reduced adipose tissue mass but in an independently generated strain of Acc2 knockout mice we observed increased whole-body and skeletal muscle FAO and a compensatory increase in muscle glycogen stores without changes in glucose tolerance, energy expenditure or fat mass in young mice (12-16 weeks). The aim of the present study was to determine whether there was any effect of age or housing at thermoneutrality $\left(29^{\circ} \mathrm{C}\right.$; which reduces total energy expenditure) on the phenotype of Acc2 knockout mice. At 42-54 weeks of age, male WT and $A c c 2^{-1-}$ mice had similar body weight, fat mass, muscle triglyceride content and glucose tolerance. Consistent with younger $A c c 2^{-1-}$ mice, aged $A c c 2^{-1-}$ mice showed increased whole-body FAO (24 $\mathrm{h}$ average respiratory exchange ratio $=0.95 \pm 0.02$ and $0.92 \pm 0.02$ for WT and $A c c 2^{-1-}$ mice respectively, $\left.P<0.05\right)$ and skeletal muscle glycogen content $(+60 \%, P<0.05)$ without any detectable change in whole-body energy expenditure. Hyperinsulinaemiceuglycaemic clamp studies revealed no difference in insulin action between groups with similar glucose infusion rates and tissue glucose uptake. Housing $A c c 2^{-1-}$ mice at $29{ }^{\circ} \mathrm{C}$ did not alter body composition, glucose tolerance or the effects of fat feeding compared with WT mice. These results confirm that manipulation of Acc2 may alter FAO in mice, but this has little impact on body composition or insulin action.
\end{abstract}
Key Words
- insulin resistance
- glucose metabolism
- metabolism
- acetyl CoA carboxylase
- energy balance

Journal of Endocrinology (2016) 228, 127-134

\section{Introduction}

The oxidation of fatty acids in cells requires transport into mitochondria where the enzymes of $\beta$-oxidation are located. This transport utilises the enzyme carnitine palmitoyl transferase (CPT)-1 and an important regulator of CPT- 1 activity is the metabolite malonyl-CoA, a product of the acetyl-CoA carboxylase (ACC) enzyme. There are two isoforms of ACC. Both Acc1 (Acaca) and Acc2 (Acacb) are expressed in the adipose tissue and liver, but the

Published by Bioscientifica Ltd 
predominant form in the muscle and heart is Acc2 (Kreuz et al. 2009). Given its localisation on the mitochondrial outer membrane, deletion or inhibition of $A c c 2$ would be expected to decrease the malonyl-CoA pool regulating CPT-1, thereby, enhancing the flux of FA into the mitochondria for oxidation. Accordingly, ACC2 was proposed to be an attractive target for the treatment of obesity on the assumption that an increase in the fatty acid utilisation would reduce fat stores. Consistent with this hypothesis, early studies using Acc2 knockout mice reported a lean phenotype with improved insulin action due to increased whole-body and muscle fatty acid oxidation (FAO) and higher energy expenditure (Abu-Elheiga et al. 2001, Abu-Elheiga et al. 2003, Choi et al. 2007). However, more recent studies using two separate strains of $A c c 2^{-/-}$mice produced using different targeting strategies and generated in different labs did not display lean phenotypes. One study showed that deletion of Acc2 produced the expected increase in muscle and whole-body FAO, but this change in substrate preference was not accompanied by altered energy expenditure, body composition or glucose tolerance in mice under both chow and high-fat diet (HFD) conditions (Hoehn et al. 2010). These $A c c 2^{-1-}$ mice did, however, display a robust increase in muscle glycogen content and an elevation in conversion of carbohydrate to lipid, indicative of a re-channelling of excess carbohydrate into other anabolic pathways (Hoehn et al. 2010). Olson et al. (2010) also reported that whole-body and muscle specific deletion of $A c c 2^{-1-}$ mice had limited influence on metabolic phenotype and body composition in mice.

FAO theoretically produces more ATP per carbon oxidised to $\mathrm{CO}_{2}$ than glucose but consumes $6-9 \%$ more oxygen for this process (Turner et al. 2014). This suggests that producing the same amount of ATP from FAO could be less efficient than carbohydrate oxidation in terms of ATP produced per oxygen consumed. The first aim in this study was to determine whether older $A c c 2^{-1-}$ mice displayed alterations in body composition and insulin action, due to chronic changes in FAO over a more prolonged timeframe than our previous studies. Furthermore, because metabolic rate decreases with increasing ambient temperature (Abreu-Vieira et al. 2015) and housing temperature is known to have a marked effect on the whole-body substrate oxidation and metabolic profile (Liu et al. 2003, Castillo et al. 2011), our second aim was to determine whether the shift in fuel preference to fatty acids in $A c c 2^{-/-}$mice would alter the response to a chow and HFD when mice were housed under conditions of thermoneutrality.

\section{Materials and methods}

All surgical and experimental procedures performed were approved by the Garvan Institute/St Vincent's Hospital Animal Ethics Committee and were in accordance with the National Health and Medical Research Council of Australia's guidelines on animal experimentation.

\section{Animals}

$A c c 2^{-1-}$ mice were generated as described previously (Hoehn et al. 2010). Acc2 ${ }^{-1-}$ and WT littermates were communally housed in temperature-controlled $\left(22 \pm 0.5^{\circ} \mathrm{C}\right.$ standard housing or $29 \pm 0.5^{\circ} \mathrm{C}$ for thermoneutral studies) and light-controlled ( $12 \mathrm{~h}$ light: $12 \mathrm{~h}$ darkness cycle) rooms. They were fed ad libitum a standard chow diet (21\% of calories from protein, $8 \%$ from fat, $71 \%$ from carbohydrate; Rat Maintenance Diet; Gordon Specialty Feeds, Sydney, NSW, Australia) or a HFD made in-house ( $45 \%$ of calories from fat, $20 \%$ from protein and $35 \%$ from carbohydrates) based on rodent diet no. D12451 (Research Diets, New Brunswick, NJ, USA). Mice were studied at $\sim 18$ or 50 weeks of age. For thermoneutral studies, animals were acclimatised to the warmer room for $2-4$ weeks prior to dietary intervention (4 weeks).

\section{Respirometry}

Oxygen consumption rate $\left(\mathrm{VO}_{2}\right)$ and respiratory exchange ratio (RER) were measured under a consistent environmental temperature $\left(22^{\circ} \mathrm{C}\right)$ using an indirect calorimetry system (Oxymax series, Columbus Instruments, Columbus, OH, USA). The airflow was $0.61 / \mathrm{min}$ and measurements were recorded after a $24 \mathrm{~h}$ acclimatisation period in the metabolic chamber. $\mathrm{VO}_{2}$ and $\mathrm{CO}_{2}$ were measured in individual mice at $27 \mathrm{~min}$ intervals over a $24 \mathrm{~h}$ period.

\section{Glucose tolerance test and fat mass determination}

Mice were fasted for $5 \mathrm{~h}$ and were then injected intraperitoneally with glucose $(2 \mathrm{~g} / \mathrm{kg})$ and blood glucose levels were monitored over time (ipGTT). Total fat mass was determined by dual X-ray absorptiometry using a PIXImus small-animal densitometer and associated software (PIXImus II; GE Medical Systems, Madison, WI, USA).

\section{Surgical procedures}

Older mice were anaesthetised with isoflurane anaesthesia ( $4 \%$ induction, $1.5-2 \%$ maintenance) for insertion of

Published by Bioscientifica Ltd 
catheters into the left carotid artery and right jugular vein. Free catheter ends were tunnelled under the skin, externalised at the neck and sealed. Mice were then singly housed and monitored daily. Catheters were flushed every 1-2 days with heparinised saline to maintain patency.

\section{Hyperinsulinaemic-euglycaemic clamp}

Approximately $4-7$ days post-surgery, and after a $\sim 5 \mathrm{~h}$ fast, a hyperinsulinaemic-euglycaemic clamp was conducted. Mice were conscious, unrestrained and were not handled during the procedure to minimise stress. At $-90 \mathrm{~min}$, a primed $(5 \mu \mathrm{Ci})$ continuous infusion $(0.05 \mu \mathrm{Ci} / \mathrm{min})$ of $\left[3,{ }^{3} \mathrm{H}\right]$ glucose (PerkinElmer, Glen Waverley, Victoria, Australia) was commenced. At $-30,-20,-10$ and 0 samples were collected for basal glucose turnover $\left(\mathrm{R}_{\mathrm{d}}\right)$ and glucose and insulin levels ( -30 and 0 ). At time 0 , the rate of $\left[3,{ }^{3} \mathrm{H}\right]$ glucose was increased to $(0.1 \mu \mathrm{Ci} / \mathrm{min})$ and primed to $(16 \mathrm{mU} / \mathrm{kg})$, continuous $(4 \mathrm{mU} / \mathrm{kg}$ per $\mathrm{min}$ ) infusion of insulin commenced (Actrapid, Novo Nordisk, Copenhagen, Denmark). Glucose (25\%) was infused at a variable rate to maintain glycaemia at $\sim 8 \mathrm{mM}$. Once blood glucose was stable, four sequential samples were taken for glucose turnover and insulin determination. A bolus of $2\left[{ }^{14} \mathrm{C}\right]$ deoxyglucose $(13 \mu \mathrm{Ci}$; PerkinElmer $)$ was then administered and blood sampled at 2, 5, 10, 15, 20 and $30 \mathrm{~min}$ for measurement of glucose uptake into specific tissues. Animals were then euthanised and organs removed, snap frozen in liquid nitrogen and stored at $-80{ }^{\circ} \mathrm{C}$ for further analysis. This protocol is based on Ayala et al. (2006) and Charbonneau \& Marette (2010).

\section{Analytical methods}

Blood and plasma glucose levels were determined using an Accu-check II glucometer (Roche Diagnostics, Castle Hill, NSW, Australia). Insulin levels were determined using a sensitive rat RIA kit (Millipore, Missouri, USA). Triglyceride and glycogen content were measured in tissues as described previously (Bruce et al. 2007, Hoy et al. 2009). The rate of basal and clamp glucose disappearance $\left(\mathrm{R}_{\mathrm{d}}\right)$ was determined using steady-state equations. Clamp hepatic glucose output was determined by subtracting the glucose infusion rate (GIR) from $R_{d}$. For determination of tissue glucose uptake, tissue samples were homogenised in water. After centrifugation, one aliquot was counted to determine total $2\left[{ }^{14} \mathrm{C}\right] \mathrm{DG}$ and $2\left[{ }^{14} \mathrm{C}\right] \mathrm{DGP}$ radioactivity. Another aliquot was run through a column of AG 1-X8 resin (Bio-Rad Laboratories) which retains $2\left[{ }^{14} \mathrm{C}\right] \mathrm{DGP}$ and elutant containing $2\left[{ }^{14} \mathrm{C}\right] \mathrm{DG}$ was counted. $2\left[{ }^{14} \mathrm{C}\right] \mathrm{DGP}$ tissue is the difference between total ${ }^{14} \mathrm{C}$ and $2\left[{ }^{14} \mathrm{C}\right] \mathrm{DG}$ measures. Using this $2\left[{ }^{14} \mathrm{C}\right] \mathrm{DGP}$ tissue, glucose uptake into tissues was determined using the following equation:

$R g^{\prime}=\left(\frac{2\left[{ }^{14} \mathrm{C}\right] \mathrm{DGP}_{\text {tissue }}}{\text { AUC } 2\left[{ }^{14} \mathrm{C}\right] \mathrm{DG}_{\text {plasma }}}\right) \times($ arterial glucose $)$

where $2\left[{ }^{14} \mathrm{C}\right] \mathrm{DGP}$ tissue is the $2\left[{ }^{14} \mathrm{C}\right] \mathrm{DGP}$ radioactivity in the muscle (in dpm/g), AUC $2\left[{ }^{14} \mathrm{C}\right] D G_{\text {plasma }}$ is the area under the plasma $2\left[{ }^{14} \mathrm{C}\right] \mathrm{DG}$ disappearance curve (in $\mathrm{dpm} / \mathrm{min}$ per $\mathrm{ml}$ ), and (arterial glucose) is the average blood glucose (in $\mathrm{mmol} / \mathrm{l}$ )(Ayala et al. 2007).

Western blotting was conducted as previously described (Brandon et al. 2015). ACC antibody was from Cell Signaling Technology (Danvers, MA, USA).

\section{Statistical analysis}

Data are expressed as means \pm s.E.M. Differences between groups were determined by $t$-test or two-way ANOVA as required. If the two-way ANOVA reached significance, a Bonferroni's post hoc test was conducted. All statistical analysis was done using GraphPad Prism (Version 6 for Windows, GraphPad Software, San Diego, CA, USA). Significance was set at $P \leq 0.05$.

\section{Results}

\section{Effect of Acc2 deletion on body weight and fat mass of 1 year old mice kept at $22{ }^{\circ} \mathrm{C}$}

Successful Acc2 deletion was determined via western blot in the gastrocnemius muscle (Fig. 1A). Since Acc2 is the predominant isoform in the muscle, there is only one band observed in the WT and no bands in $A c c 2^{-1-}$ mice.

Body weights were similar between $A c c 2^{-/-}$and WT animals (Fig. 1B). Total fat mass, as determined by DEXA, was not different between groups (Fig. 1C) and there was no difference in the weight of individual fat pads between genotypes (Fig. 1D and E).

\section{Whole-body and muscle parameters}

Whole-body calorimetry showed that, similar to younger animals (Hoehn et al. 2010), older $A c c 2^{-1-}$ mice showed increased whole-body FAO ( $24 \mathrm{~h}$ average RER $=0.95 \pm 0.02$ and $0.92 \pm 0.02$ for WT and $A c c 2^{-1-}$ mice respectively, $P<0.05$; Fig. $2 \mathrm{~A}$ and $\mathrm{B})$. This occurred without observable changes in energy expenditure (Fig. 2C and D) and without differences in glucose tolerance (Fig. 2E).

Published by Bioscientifica Ltd 
A
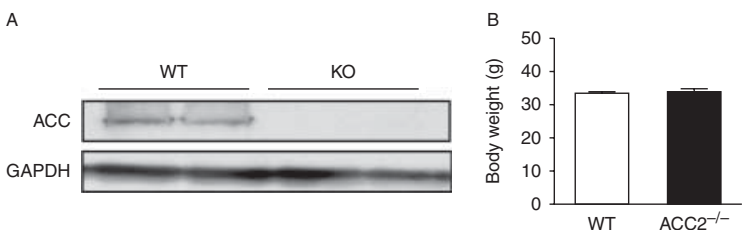
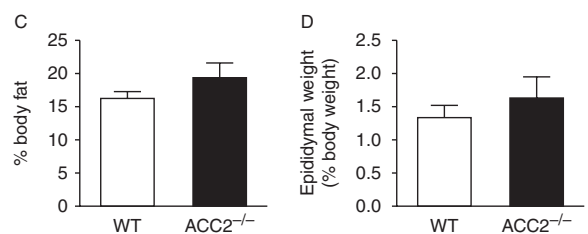

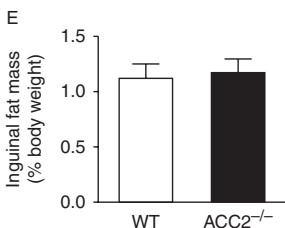

\section{Figure 1}

Body weight and fat mass are similar between WT and $A c c 2^{-1-}$ mice. (A) Representative western blot demonstrating deletion of Acc2 in gastrocnemius muscle. (B) Body weight, (C) percent fat mass as determined

There were no differences between the groups in muscle triglyceride content (Fig. 3A). However, there was an increase in muscle glycogen content in the $A c c 2^{-/-}$group (Fig. 3B).

\section{Hyperinsulinaemic-euglycaemic clamp studies}

Under basal conditions, WT and $A c c 2^{-1-}$ mice showed similar blood glucose and plasma insulin levels (Fig. 4A and B). There was also no difference in basal whole-body glucose disappearance (Fig. 4D). Under insulin-stimulated conditions, there was no difference between the groups in GIR (Fig. 4C), whole-body glucose disappearance, hepatic glucose output (Fig. 4E) or glucose uptake into various tissues (Fig. 4F), indicating similar whole-body and tissue insulin sensitivity.

\section{Effect housing at $29^{\circ} \mathrm{C}$ and HFD on body weight, fat mass and glucose tolerance of Acc2 knockout mice}

There was no observable difference between WT and $A c c 2^{-1-}$ mice housed at $29^{\circ} \mathrm{C}$ for any of the parameters measured. Animals fed a HFD were heavier when compared with the chow-fed animals irrespective of genotype (Fig. 5A). This was due to a higher fat mass in the HFD group (Fig. 5B, C and D). While there was a worsening of glucose tolerance in animals fed a HFD, this was not affected by genotype (Fig. 5E and F). Acc $2^{-1-}$ animals housed at thermoneutrality did exhibit the by DEXA and individual weights for (D) epididymal and (E) inguinal fat pads in WT and $\mathrm{ACC}^{-1-}$ mice. Data are expressed as mean \pm s.E.M. $n=8-11$ animals per group. Animals were 42-52 weeks of age.

increased glycogen content in the muscle demonstrated in mice housed at $22^{\circ} \mathrm{C}$, and this was unaffected by diet (Fig. 6A). There was no difference in triglyceride content between genotypes kept at $29^{\circ} \mathrm{C}$, but there was a clear increase in both genotypes when fed a HFD (Fig. 6B).

\section{Discussion}

The glucose-fatty acid cycle, first reported more than 50 years ago by Randle et al. (1963), describes the competition between glucose and fatty acids for oxidation in muscle and adipose tissue to provide energy to support all cellular processes (Hue \& Taegtmeyer 2009). This idea proposes that when there is excess of one type of fuel, or when one fuel substrate is preferentially oxidised, then the other is channelled into storage pathways. Our findings in $A c c 2^{-1-}$ mice, both in the present study and in our previous work (Hoehn et al. 2010), are completely consistent with this model, as the enhanced oxidation of FA without any concomitant increase in energy expenditure leads to diversion of other potential energy substrates like carbohydrate to other pathways including storage as glycogen in muscle.

Because fatty acids are a more reduced form of substrate than carbohydrate or amino acids, the complete oxidation of fatty acids theoretically yields more ATP per carbon atom than oxidation of glucose carbons. However, more oxygen atoms are consumed for complete oxidation
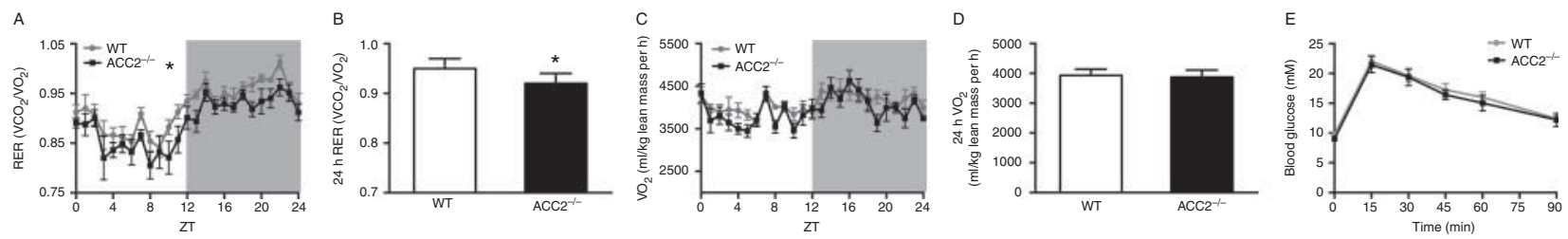

Figure 2

Deletion of $A c c 2$ increased whole-body fatty acid oxidation without altering energy expenditure or glucose tolerance. (A) Respiratory exchange ratio (RER), (B) $24 \mathrm{~h}$ average $\mathrm{RER},(\mathrm{C})$ oxygen consumption $\left(\mathrm{VO}_{2}\right),(\mathrm{D}) 24 \mathrm{~h}$
(C) 2016 Society for Endocrinology Printed in Great Britain average $\mathrm{VO}_{2}$, (E) glucose tolerance in WT and $\mathrm{ACC}^{-1-}$ mice. Data are expressed as mean \pm s.E.M. ${ }^{*} P<0.05$ vs WT (average $24 \mathrm{~h}$ values). $n=8-11$ animals per group. Animals were $42-52$ weeks of age.

Published by Bioscientifica Ltd 

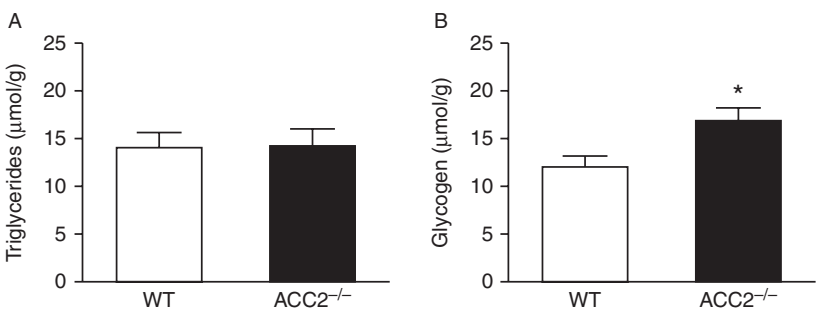

Figure 3

Muscle of $A c c 2^{-1-}$ mice has similar triglyceride and increased glycogen levels. (A) Triglyceride and (B) glycogen content in the gastrocnemius muscle of WT and $A c c 2^{-1-}$ mice. Data are expressed as mean \pm s.E.M. ${ }^{*} P<0.05$ vs WT. $n=8-11$ animals per group. Animals were $42-52$ weeks of age.

of fatty acid carbons (Turner et al. 2014) leading to the idea that increased FAO is accompanied by increased energy expenditure (as measured by oxygen consumption). Therefore, preferential whole body oxidation of FA has been hypothesised to impact on the metabolic and body composition phenotype of animals. Despite initial reports that this was the case in one line of $A c c 2^{-1-}$ mice, we, and others have firmly established that preferentially promoting the oxidation of lipid substrates through deletion of Acc2 has little effect on body composition and insulin action (Hoehn et al. 2010, Olson et al. 2010). However, because our previous findings were in younger animals, it was possible that chronic changes in FAO over the longer term may have some impact on whole-body energy metabolism that was not evident in younger mice. In the present study, examining 9- to 12-month-old $A c c 2^{-/-}$ mice, increases in whole-body FAO and glycogen deposition in muscle were still present, without any significant change in energy expenditure, body composition or insulin sensitivity as measured by the euglycaemichyperinsulinaemic clamp. Therefore, these results add further weight to our previous conclusions that increasing FAO alone, even over an extended period of time, is insufficient to alter body weight and fat mass, but instead leads to the channelling of carbohydrate into storage pathways (Hoehn et al. 2010).

The marked discrepancies between different lines of $A c c 2^{-1-}$ mouse have been documented in a range of published articles. The first $A c c 2^{-1-}$ mice generated were reported to have increased $\mathrm{FAO}$, higher energy expenditure and better insulin sensitivity (determined by clamp), despite being hyperphagic (Abu-Elheiga et al. 2001, 2003, Choi et al. 2007). These findings have not been repeated in other studies (Hoehn et al. 2010, Olson et al. 2010) and these discrepancies may be related to differences in many factors, including variations in gene-targeting strategies (Hoehn et al. 2012). That is, $A c c 2^{-1-}$ mice generated by Wakil and colleagues targeted a different exon to other
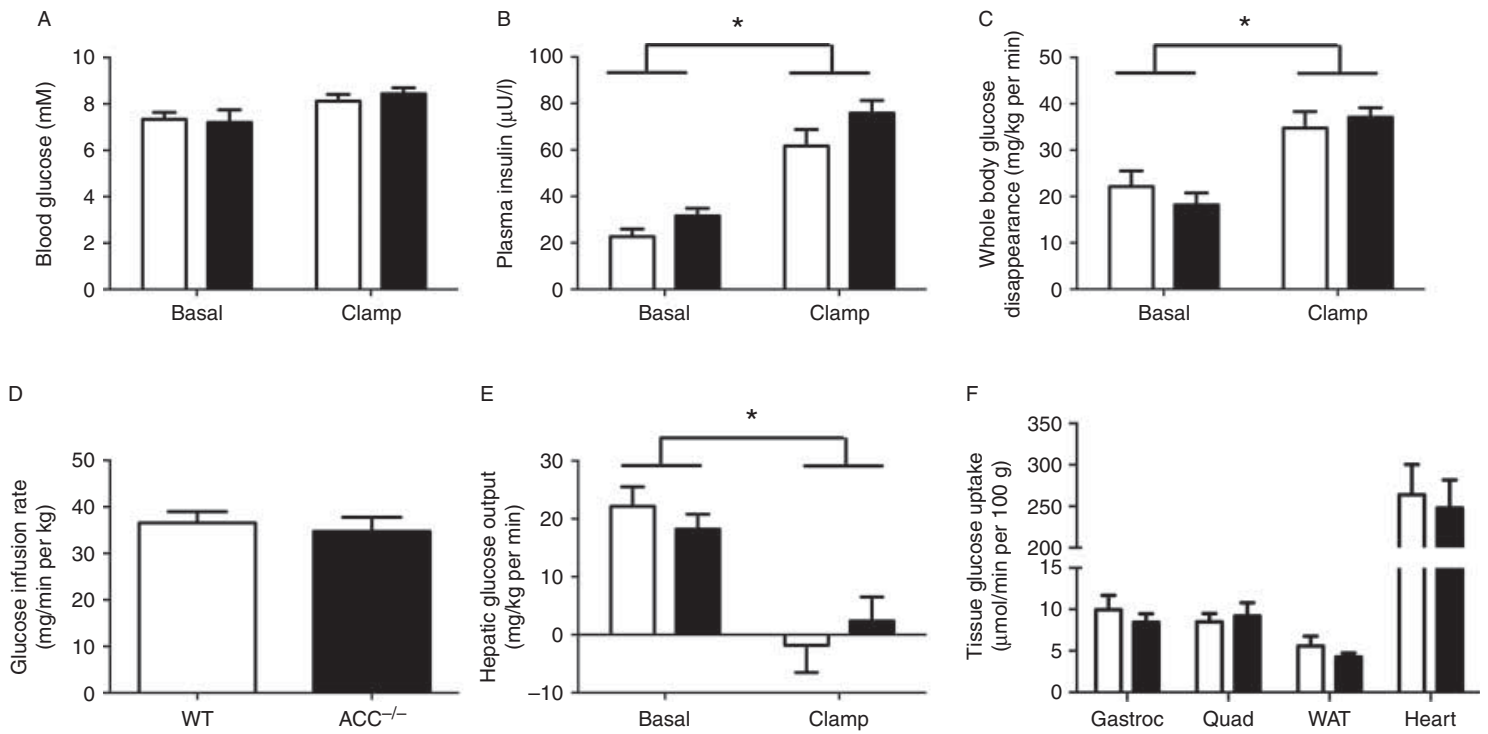

Figure 4

Hyperinsulinaemic-euglycaemic clamp studies showing $\mathrm{Acc}^{-1-}$ mice have similar insulin sensitivity to WT mice. (A) Blood glucose and (B) plasma insulin levels in the basal and insulin-stimulated conditions. (C) Glucose infusion rate. (D) Whole-body glucose disappearance and (E) hepatic glucose output in the basal and insulin-stimulated conditions. (F) Glucose uptake into muscle (quadriceps, gastrocnemius), white adipose tissue (WAT; epididymal) and heart of WT and $A c c 2^{-1-}$ mice. Data are expressed as mean \pm S.E.M. ${ }^{*} P<0.05$ vs basal state. $n=6-8$ animals per group. Animals were $42-52$ weeks of age. 
A

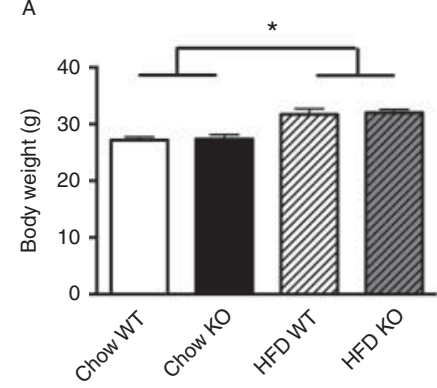

D

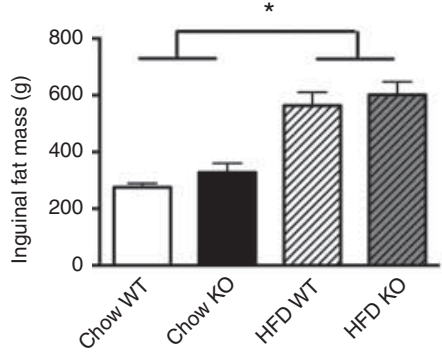

B

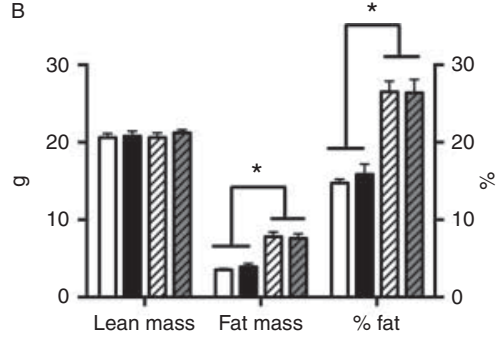

E

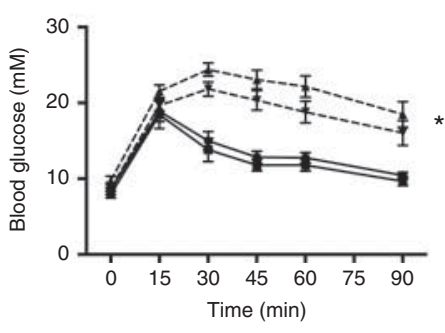

c

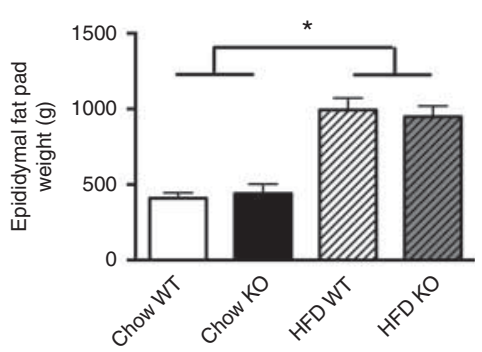

$\mathrm{F}$

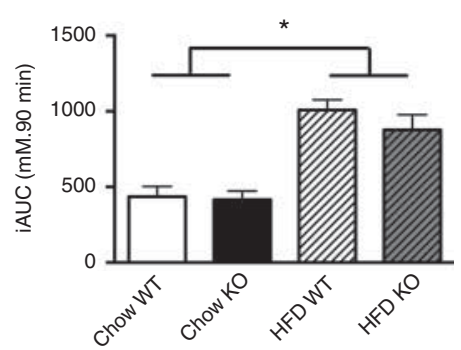

Figure 5

Housing $A c c 2^{-1-}$ mice at thermoneutral temperatures $\left(29^{\circ} \mathrm{C}\right)$ does not alter body weight, body composition or glucose tolerance on chow or highfat diet (HFD). (A) Body weight, (B) body composition as determined by DEXA, (C) epididymal and (D) inguinal fat mass weights, (E) ipGTT curve and

groups and their mice are also engineered to overexpress hypoxanthine-guanine phosphoribosyltransferase (Hprt) (presumably in every cell of the animal), an important enzyme in the purine salvage pathway, which is not present in WT mice (Abu-Elheiga et al. 2001). Although there is little information about the effects of overexpression of Hprt, the deletion or mutation of this gene in humans causes Lesch-Nyhan syndrome, an X-linked recessive disorder characterised by uric acid overproduction and neurological manifestations (Torres \& Puig 2007). However, in addition to the $A c c 2^{-1-}$ mouse line used for the current studies, Olson et al. (2010) reported no alterations in body weight, fat mass or glucose homeostasis in different lines of whole-body and muscle-specific $A c c 2$ knockouts or if the $A c c 2^{-1-}$ were crossed with obese leptin-deficient mice $(o b / o b)$.

There are some recent data showing that treatment of obese, insulin-resistant $d b / d b$ mice for 70 days with a selective inhibitor of ACC2 can lower circulating glucose and triglycerides and improve glucose tolerance and glucose uptake in muscle (Glund et al. 2012). However, the inhibitor had no effect on body weight or fat mass and neither energy expenditure nor whole-body fat oxidation were determined in this study. Therefore, it is not clear whether the beneficial effects of this inhibitor were due
(F) iAUC in chow and HFD mice. White bars, chow WT; black bars, chow $A c c 2^{-1-}$; white hatched bars, HFD WT; grey hatched bars, HFD Acc2 ${ }^{-1-}$. $* P<0.05$ effect of diet. $n=5-11$ animals per group. Animals were $16-20$ weeks of age.

solely to increased FAO relieving lipid-induced insulin resistance in muscle or whether a similar improvement would be seen if the ACC2 inhibitor was delivered to HFD-fed animals.

Housing at, or near, thermoneutral temperature for mice should be a consideration when assessing phenotypes, especially in relation to potential differences in energy metabolism and obesity. Standard housing conditions for mice vary between facilities but are normally
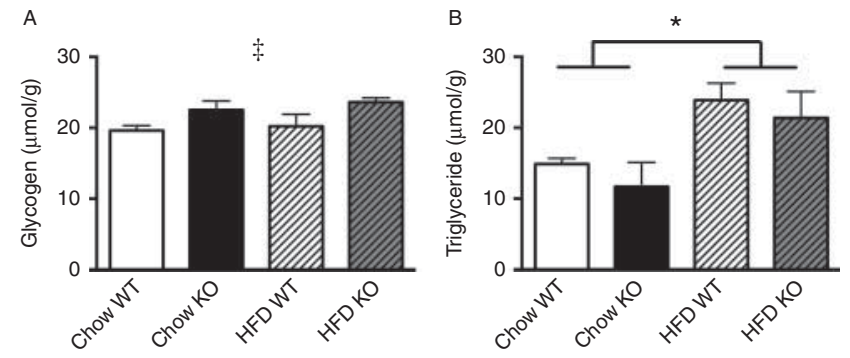

\section{Figure 6}

Acc2 ${ }^{-1-}$ mice have similar muscle triglyceride content that increases equally after a high-fat diet, while there is an increased muscle glycogen content in $A c c 2^{-1-}$ mice that is unaffected by diet. (A) Glycogen and (B) triglyceride content in the gastrocnemius muscle of WT and $A c c 2^{-1-}$ mice. Data are expressed as mean \pm s.E.M. ${ }^{\ddagger} P<0.05$ effect of genotype; ${ }^{*} P<0.05$ effect of diet. $n=5-11$ animals per group. Animals were $16-20$ weeks of age.

Published by Bioscientifica Ltd 
between 20 and $25{ }^{\circ} \mathrm{C}$, the thermoneutral conditions for lightly clothed humans. Mice, however, have a thermoneutral zone that is closer to $30^{\circ} \mathrm{C}$ (Maloney et al. 2014). This means that under most housing conditions, mice are subject to chronic cold stress. This is an important aspect to consider since it has been shown that this temperature difference can change parameters of the cardiovascular system (e.g. heart rate), response to infections and metabolic rate (reviewed in Overton (2010)). Interestingly, there are examples in the literature where ambient temperature has a significant effect on phenotype. The first example is the UCP1 deficient mouse, which was reported to be resistant to a HFD weight gain when housed at standard temperatures $\left(20^{\circ} \mathrm{C}\right)$, but when the temperature was raised to $27^{\circ} \mathrm{C}$, these animals showed accelerated body weight gain (Liu et al. 2003). Another example is the type 2 deiodinase (Dio2) knockout mouse, which had better glucose tolerance than WT animals on a chow diet at standard housing temperature but this was lost when animals were housed at $30^{\circ} \mathrm{C}$. In fact, Dio $2^{-1-}$ mice were more glucose intolerant when placed on a HFD at this increased temperature (Castillo et al. 2011). In the present study, $A c c 2^{-/-}$mice housed at $29^{\circ} \mathrm{C}$ displayed no differences compared with WT littermates with regard to body weight, fat mass or glucose tolerance on a chow diet and all these parameters changed similarly when both genotypes were placed on a HFD.

In summary, this study provides further evidence that deletion of $A c c 2$, although increasing whole-body FAO, does not alter energy expenditure, fat mass or insulin sensitivity even when genotype-dependent differences in substrate oxidation have been present for an extended period of time or animals are housed under conditions of thermoneutrality. These studies strongly support the view that switching between different substrates for energy metabolism, without any alteration in total fuel oxidation, is insufficient to alter body weight and that changes in total energy expenditure are required to drive weight loss.

\section{Declaration of interest}

The authors declare that there is no conflict of interest that could be perceived as prejudicing the impartiality of the research reported.

\section{Funding}

This work was supported by a National Health and Medical Research Council (NHMRC) Program grant (535921) to D E J, E W K and G J C. D E J and G J C are currently supported by NHMRC Research Fellowships and NT is supported by an Australian Research Council (ARC) Future Fellowship.
Author contribution statement

$A E B, N T, G J C$ and E W K conceived and designed the experiments; A E B, $N$ T, E S and S J L performed the experiments; A E B, N T and G J C analysed the data; A E B, N T, E W K, D E J, K L H and G J C wrote the paper.

\section{Acknowledgements}

The authors would like to thank the staff of the Garvan Biological Testing Facility.

\section{References}

Abreu-Vieira G, Xiao C, Gavrilova O \& Reitman ML 2015 Integration of body temperature into the analysis of energy expenditure in the mouse. Molecular Metabolism 4 461-470. (doi:10.1016/j.molmet.2015.03.001)

Abu-Elheiga L, Matzuk MM, Abo-Hashema KA \& Wakil SJ 2001 Continuous fatty acid oxidation and reduced fat storage in mice lacking acetyl-CoA carboxylase 2. Science 291 2613-2616. (doi:10.1126/science.1056843)

Abu-Elheiga L, Oh W, Kordari P \& Wakil SJ 2003 Acetyl-CoA carboxylase 2 mutant mice are protected against obesity and diabetes induced by high-fat/high-carbohydrate diets. PNAS 100 10207-10212. (doi:10.1073/pnas.1733877100)

Ayala JE, Bracy DP, McGuinness OP \& Wasserman DH 2006 Considerations in the design of hyperinsulinemic-euglycemic clamps in the conscious mouse. Diabetes 55 390-397. (doi:10.2337/diabetes.55.02.06.db050686)

Ayala JE, Bracy DP, Julien BM, Rottman JN, Fueger PT \& Wasserman DH 2007 Chronic treatment with sildenafil improves energy balance and insulin action in high fat-fed conscious mice. Diabetes 56 1025-1033. (doi:10.2337/db06-0883)

Brandon AE, Tid-Ang J, Wright LE, Stuart E, Suryana E, Bentley N, Turner N, Cooney GJ, Ruderman NB \& Kraegen EW 2015 Overexpression of SIRT1 in rat skeletal muscle does not alter glucose induced insulin resistance. PLoS ONE 10 e0121959. (doi:10.1371/journal.pone.0121959)

Bruce CR, Brolin C, Turner N, Cleasby ME, van der Leij FR, Cooney GJ \& Kraegen EW 2007 Overexpression of carnitine palmitoyltransferase I in skeletal muscle in vivo increases fatty acid oxidation and reduces triacylglycerol esterification. American Journal of Physiology. Endocrinology and Metabolism 292 E1231-E1237. (doi:10.1152/ajpendo. 00561.2006)

Castillo M, Hall JA, Correa-Medina M, Ueta C, Kang HW, Cohen DE \& Bianco AC 2011 Disruption of thyroid hormone activation in type 2 deiodinase knockout mice causes obesity with glucose intolerance and liver steatosis only at thermoneutrality. Diabetes 60 1082-1089. (doi:10.2337/db10-0758)

Charbonneau A \& Marette A 2010 Inducible nitric oxide synthase induction underlies lipid-induced hepatic insulin resistance in mice: potential role of tyrosine nitration of insulin signaling proteins. Diabetes 59 861-871. (doi:10.2337/db09-1238)

Choi CS, Savage DB, Abu-Elheiga L, Liu ZX, Kim S, Kulkarni A, Distefano A, Hwang YJ, Reznick RM, Codella R et al. 2007 Continuous fat oxidation in acetyl-CoA carboxylase 2 knockout mice increases total energy expenditure, reduces fat mass, and improves insulin sensitivity. PNAS 104 16480-16485. (doi:10.1073/pnas.0706794104)

Glund S, Schoelch C, Thomas L, Niessen HG, Stiller D, Roth GJ \& Neubauer H 2012 Inhibition of acetyl-CoA carboxylase 2 enhances skeletal muscle fatty acid oxidation and improves whole-body glucose homeostasis in db/db mice. Diabetologia 55 2044-2053. (doi:10.1007/ s00125-012-2554-9)

Hoehn KL, Turner N, Swarbrick MM, Wilks D, Preston E, Phua Y, Joshi H, Furler SM, Larance M, Hegarty BD et al. 2010 Acute or chronic upregulation of mitochondrial fatty acid oxidation has no net effect on

Published by Bioscientifica Ltd 
whole-body energy expenditure or adiposity. Cell Metabolism 11 70-76. (doi:10.1016/j.cmet.2009.11.008)

Hoehn KL, Turner N, Cooney GJ \& James DE 2012 Phenotypic discrepancies in acetyl-CoA carboxylase 2-deficient mice. Journal of Biological Chemistry 287 15801; author reply 15802. (doi:10.1074/ jbc.O112.356915)

Hoy AJ, Brandon AE, Turner N, Watt MJ, Bruce CR, Cooney GJ \& Kraegen EW 2009 Lipid and insulin infusion-induced skeletal muscle insulin resistance is likely due to metabolic feedback and not changes in IRS-1, Akt or AS160 phosphorylation. American Journal of Physiology. Endocrinology and Metabolism 297 E67-E75. (doi:10.1152/ajpendo. 90945.2008)

Hue L \& Taegtmeyer H 2009 The Randle cycle revisited: a new head for an old hat. American Journal of Physiology. Endocrinology and Metabolism 297 E578-E591. (doi:10.1152/ajpendo.00093.2009)

Kreuz S, Schoelch C, Thomas L, Rist W, Rippmann JF \& Neubauer H 2009 Acetyl-CoA carboxylases 1 and 2 show distinct expression patterns in rats and humans and alterations in obesity and diabetes. Diabetes/Metabolism Research and Reviews 25 577-586. (doi:10.1002/ dmrr.997)

Liu X, Rossmeisl M, McClaine J, Riachi M, Harper ME \& Kozak LP 2003 Paradoxical resistance to diet-induced obesity in UCP1-deficient mice.
Journal of Clinical Investigation 111 399-407. (doi:10.1172/ JCI200315737)

Maloney SK, Fuller A, Mitchell D, Gordon C \& Overton JM 2014 Translating animal model research: does it matter that our rodents are cold? Physiology 29 413-420. (doi:10.1152/physiol. 00029.2014)

Olson DP, Pulinilkunnil T, Cline GW, Shulman GI \& Lowell BB 2010 Gene knockout of Acc2 has little effect on body weight, fat mass, or food intake. PNAS 107 7598-7603. (doi:10.1073/pnas.0913492107)

Overton JM 2010 Phenotyping small animals as models for the human metabolic syndrome: thermoneutrality matters. International Journal of Obesity 34(Suppl 2) S53-S58. (doi:10.1038/ijo.2010.240)

Randle PJ, Garland PB, Hales CN \& Newsholme EA 1963 The glucose fattyacid cycle. Its role in insulin sensitivity and the metabolic disturbances of diabetes mellitus. Lancet 1 785-789. (doi:10.1016/S01406736(63)91500-9)

Torres RJ \& Puig JG 2007 Hypoxanthine-guanine phosophoribosyltransferase (HPRT) deficiency: Lesch-Nyhan syndrome. Orphanet Journal of Rare Diseases 2 48. (doi:10.1186/1750-1172-2-48)

Turner N, Cooney GJ, Kraegen EW \& Bruce CR 2014 Fatty acid metabolism, energy expenditure and insulin resistance in muscle. Journal of Endocrinology 220 T61-T79. (doi:10.1530/JOE-13-0397)

Received in final form 29 November 2015

Accepted 14 December 2015

Accepted Preprint published online 14 December 2015
(C) 2016 Society for Endocrinology Printed in Great Britain
Published by Bioscientifica Ltd. 